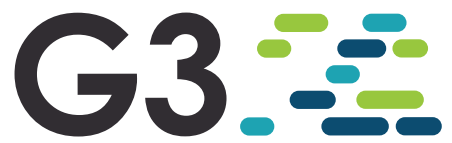

Genes | Genomes | Genetics

INVESTIGATIONS

\title{
Detecting dipicolinic acid production and biosynthesis pathways in Bacilli and Clostridia
}

\author{
Benjamin Gordon*,1, Paul Duellman*, Anthony Salvucci* and Marthah De Lorme* \\ *Agrinos Global Research \& Development Center, Davis, CA 95618
}

\section{INTRODUCTION}

Bacterial spores are highly resistant structures in a dormant state, with little, if any, detectable metabolic activity (McKenney et al. 2013) (Figure 1). Spores are formed in response to adverse environmental conditions and spore formation, or sporulation, generally occurs when bacteria are challenged by nutritional stress (Driks 2002; Errington 2003; Piggot and Hilbert 2004). Spores can remain alive for extended periods of time and possess the ability to reactivate if nutrients become available and conditions are favorable (Moir 2003; Setlow 2003; Paredes-Sabja et al. 2011). Spores can survive many conditions that would otherwise destroy vegetative

Manuscript compiled: Wednesday $9^{\text {th }}$ October, 2019

${ }^{1}$ Corresponding author: Agrinos, 279 Cousteau Place, Suite 100, Davis, CA 95618-7764.

E-mail: benjamin.gordon@agrinos.com

cells. The unique architecture of spores, such as the spore coat, cortex, and core, explains in large part their resistance to stresses and their ability to survive under extreme conditions (Henriques and Moran 2007).

Firmicutes are characterized by their ability to produce endospores (Figure 2-6), and compared to other spore-forms endospores are many times more resistant to oxidizing agents, heat, desiccation, and radiation (Setlow 1995). Pyridine-2,6-dicarboxylic acid, or dipicolinic acid (DPA) is an important component of bacterial endospores (Powell 1953). It has been shown that DPA is located in the spore core, and can represent $5-14 \%$ of endospore dry weight (Murrell 1969). DPA is maintained within intact endospores, and can be degraded under aerobic (Arima and Kobayashi 1962; Taylor and Amador 1988; Amador and Taylor 1990) and anaerobic (Seyfried and Schink 1990) conditions after it is released during spore germination. Dipicolinic acid forms a complex with calcium 


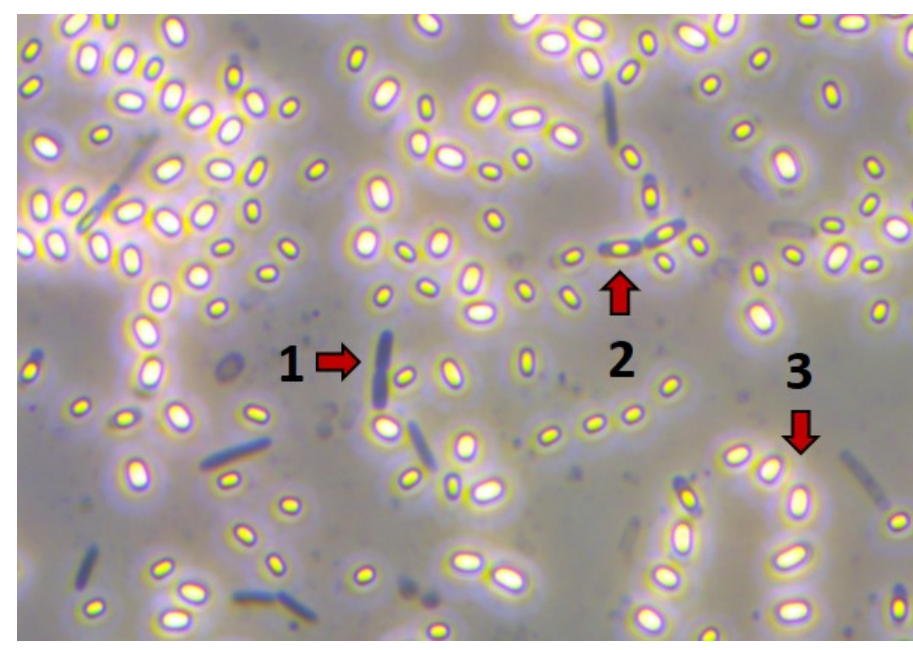

Figure 1 Phase-contrast microscopy (100X) of Bacillus sp. AS739 with examples of vegetative cells (1), endospores (2), and mature spores (3) visible.

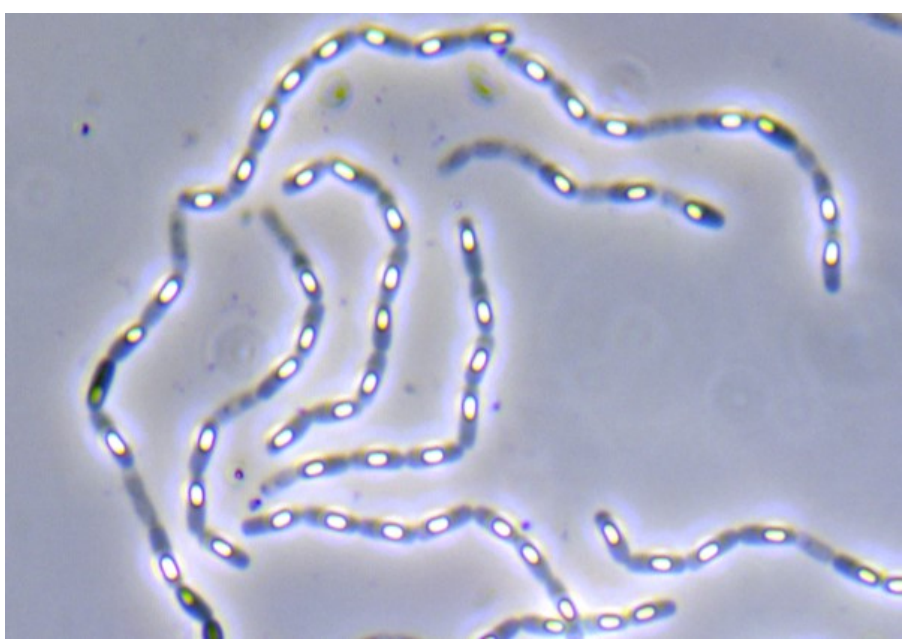

Figure 2 Phase-contrast microscopy (100X) of Bacillus marisflavi AS47 with endospores visible throughout.

strains such as Clostridium acetobutylicum and C. beijerinckii, as well as human pathogens such as $C$. perfringens, $C$. botulinum and $C$. tetani. Osburn et al. (2010) implicated an electron transfer flavoprotein $\alpha$-chain (etfA) that is directly involved in DPA synthesis in $C$. perfringens using a modified version of the Bach and Gilvarg assay system (Bach and Gilvarg 1966; Orsburn et al. 2010). We hypothesized that other members of the Clostridium (cluster I) such as $C$. beijerinckii, C. carboxidivorans, C. scatologenes, and C. tyrobutyricum, use the same or similar biosynthesis pathways.

DPA can be detected by a range of analytical techniques (Beverly et al. 1996; Yilmaz et al. 2010; Cowcher et al. 2013; Wang et al. 2011). The terbium dipicolinate fluorescence method (Rosen et al. 1997; Hindle and Hall 1999) is both tractable and sensitive, allowing the detection of nanomolar concentrations. This technique is therefore appropriate for testing if the genera hypothesized to produce DPA (Brevibacillus, Fontibacillus, Lysinibacillus, Rummeliibacillus, and Terribacillus) do in fact have the capacity for DPAproduction. The terbium dipicolinate fluorescence method can also be used to establish that Clostridia such as $C$. beijerinckii, $C$. carboxidivorans, C. scatologenes, and C. tyrobutyricum produce DPA prior to sequencing and genomic evaluation to look for $d p a A B$ and etfA DPA biosynthesis gene homologues.

In the present study, bacteria isolated from soil and a microbial product were taxonomically identified using $16 \mathrm{~S}$ rRNA sequence analyses. Presumptive endospore-forming bacteria were then screened for DPA production in vitro. DPA detection was followed by whole genome-sequencing to confirm taxonomic identifications at the species-level and to examine whether known DPA biosynthesis pathways were present.

\section{MATERIALS AND METHODS}

\section{Strain Isolation and Initial Identification}

All strains used were isolated from either bulk soil or from a sample of HYT® A (Table S1) (Agrinos, https://agrinos.com). Strains were then repeatedly streaked onto semi-solid media until isogenic. Initial taxonomic classifications were made using $16 \mathrm{~S}$ rRNA gene sequences. Full length $16 \mathrm{~S}$ genes were amplified from each strain using genomic DNA and/or colonies as the PCR template (27F, 5'-AGRGTTTGATCMTGGCTCAG-3'; 1492R, 5'-GGTTACCTTGTTACGACTT-3'; following (Singer et al. 2016) with minor modifications). PCR products were sequenced directly ions within the endospore core. This complex binds free water molecules causing dehydration of the spore. As a result, the heat resistance of macromolecules within the core increases (Gerhardt 1989). In addition, the calcium-dipicolinic acid complex also functions to protect DNA from heat denaturation by inserting itself between the nucleobases, thereby increasing the stability of DNA (Moeller et al. 2014).

In Bacilli, the DPA biosynthetic pathway has been well characterized (Wolska et al. 2007). In B. subtilis, the DPA synthetic pathway is encoded by four operons: $\operatorname{dap} G$, asd, dap $A$ and $d p a A B$. Asparatate kinase, encoded by $\operatorname{dap} G$, is responsible for the first step of the biosynthesis cascade, producing L-4-aspartyl phosphate from L-aspartate. Aspartate-semialdehyde dehydrogenase, encoded by asd, is responsible for the second step, producing L-aspartate 4semialdehyde. Dihydrodipicolinate synthase, encoded by dap $A$ is responsible for the third step, producing L-2,3-dihydrodipicolinate (Takahashi et al. 2015). These steps are also used in lysine biosynthesis. DPA synthase which is responsible for the production of DPA, is encoded by $d p a A B$. Dipicolinate synthase subunit A (dpaA, otherwise known as spoVFA) encodes a putative dehydrogenase, and dipicolinate synthase subunit $\mathrm{B}(\mathrm{dpaB}$, otherwise known as spoVFB) appears to be a flavoprotein (Daniel and Errington 1993).

The major genera identified as endospore forming bacteria include Bacillus, Paenibacillus, and Clostridium (Fritze 2004; Logan and Halket 2011; Galperin 2013). Since 1990, the genus Bacillus has been split into several families and genera of endospore-forming bacteria based on 16S rRNA analysis (Galperin 2013). The unifying characteristic of these bacteria is that they are Gram-positive, form endospores, and aerobic. An increased concentration of DPA is a biochemical hallmark for endosporulating bacteria such as $B$. subtilis (Piggot and Hilbert 2004). We therefore hypothesized that strains capable of sporulating and previously classified as Bacillus, such as Brevibacillus, Fontibacillus, Lysinibacillus, Rummeliibacillus, and Terribacillus should produce DPA and contain the same set of genes responsible for DPA synthesis in Bacilli.

Work by others has shown that members of the Clostridium sensu stricto (cluster I) lack genes with significant homology to $d p a A B$ (Stragier 2002; Onyenwoke et al. 2004) but nevertheless produce DPA during sporulation (Paredes-Sabja et al. 2008). This cluster is particularly important due to the presence of industrially useful 
bioRxiv preprint doi: https://doi.org/10.1101/803486; this version posted October 16,2019 . The copyright holder for this preprint (which was not certified by peer review) is the author/funder, who has granted bioRxiv a license to display the preprint in perpetuity. It is made available under aCC-BY-NC-ND 4.0 International license.

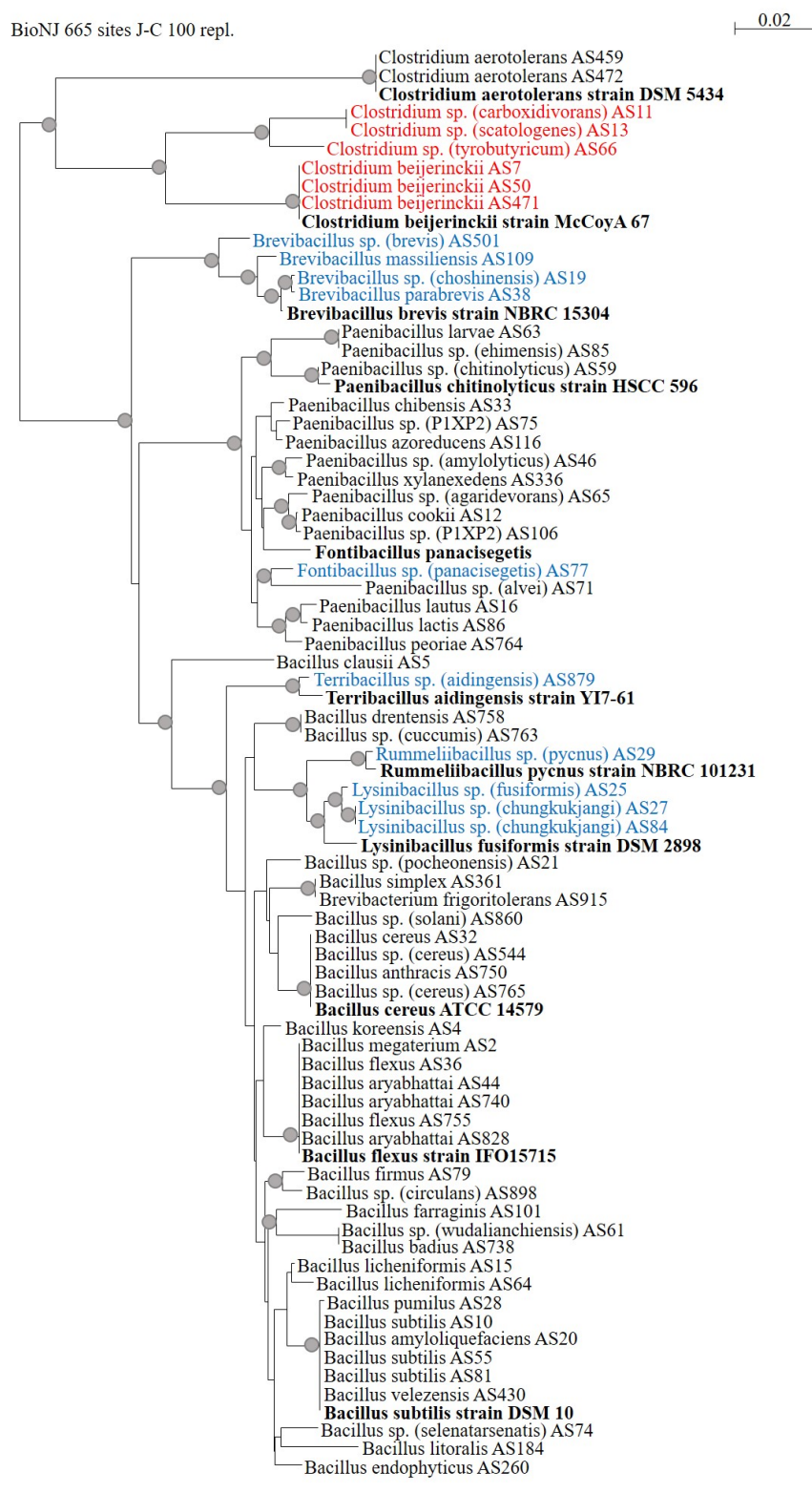

Figure 3 Neighbor-joining tree representing 16S rRNA-based phylogenetic distrtibution of strains assayed herein. Reference strains are highlighted in bold. Recently re-classified Bacilli and Paenibacilli experimentally demonstrated as producing DPA are highlighted in blue. Strains where known DPA synthase genes were not detectable are highlighted in red. Bootstrap support of $>70 \%$ is notated by grey circles at branch points (Hillis and Bull 1993). using the forward and reverse PCR primers. The high-quality sequence traces were then analyzed and a BLAST analysis was performed using the NCBI $16 \mathrm{~S}$ ribosomal RNA sequence database (Madden 2013).

\section{Terbium Dipicolinate Fluorescence Assay}

Prior to testing, strains were grown as follows. Aerobic strains were cultured on Trypticase Soy Agar (i.e. TSA; Tryptone $17 \mathrm{~g} / \mathrm{L}$, Soytone $3 \mathrm{~g} / \mathrm{L}$, Dextrose $2.5 \mathrm{~g} / \mathrm{L}$, Sodium chloride $5 \mathrm{~g} / \mathrm{L}$, Dipotassium phosphate $2.5 \mathrm{~g} / \mathrm{L}$, Agar $15 \mathrm{~g} / \mathrm{L}$ ) in a static incubator at $30^{\circ}$ for up to three days. Anaerobic strains were cultured on Reinforced Clostridial Medium (i.e. RCM; BD Difco ${ }^{\mathrm{TM}}$ Reinforced Clostridial Medium, Cat No. 218081) in a static incubator at $35^{\circ}$ for up to five days.

All cultures were visualized using phase-contrast microscopy at 100X magnification to verify the presence of refractile spores (Bulla et al. 1969). A modified version of the protocol used by Hindle and Hall (1999) was used to detect the presence of DPA. Using a sterile disposable loop, a $1 \mu l$ loopful was taken off a plate and resuspended in $10 \mathrm{ml}$ of sodium acetate buffer $(0.2 \mathrm{M}, \mathrm{pH}$ 5) in screw cap glass test tubes. Samples were autoclaved for 15 minutes at $121^{\circ}$ to heat the spores and release any DPA. Samples were then cooled for $10 \mathrm{~min}$ in a room temperature $\left(22^{\circ}\right)$ water bath. Following cooling, for each sample $100 \mu \mathrm{l}$ was mixed with $100 \mu \mathrm{l}$ of terbium chloride solution $(\mathrm{TbCl} 3,30 \mu \mathrm{M})$ in wells of a 96-well flat-bottomed clear microtiter plate. Fluorescence was measured with a BioTek ${ }^{\circledR}$ Cytation 5 Multi-Mode Reader (BioTek Instruments, Inc., https:/ /www.biotek.com/) using time resolved fluorescence (delay $50 \mu \mathrm{s}$, excitation wavelength $272 \mathrm{~nm}$, emission wavelength $540 \mathrm{~nm}$ ) (Brandes Ammann et al. 2011). Strains testing higher than negative controls, with a fluorescence intensity of more than 10,000 relative fluorescence units, and endospores visible with phase-contrast microscopy were considered DPA-producers.

\section{Whole-genome sequencing and Bioinformatic Analysis}

Whole-genome sequencing was performed by CoreBiome (CoreBiome, Inc., https://www.corebiome.com). Briefly, isolates were grown in appropriate liquid culture. A minimum of $1 \times 10^{9}$ cells were spun down and the supernatant removed prior to freezing at $-20^{\circ}$. Samples were then sent to CoreBiome for DNA extraction, followed by whole-genome sequencing, assembly, and annotation using their StrainView ${ }^{\mathrm{TM}}$ whole-genome shotgun sequencing service. Genome assembly quality was assessed using QUAST (Gurevich et al. 2013). Whole-genome sequence annotation was performed using Prokka (https://github.com/tseemann/prokka) (Seemann 2014). 16S sequences were identified using Barrnap (https://github.com/tseemann/barrnap). To assign function to CDS features, a core set of well characterized proteins are first searched using BLAST+, then a series of slower but more sensitive HMM databases are searched using HMMER3 (http://hmmer.org) (Finn et al. 2011).

\section{Phylogenetics}

For each sequence, a BLAST analysis was performed using the NCBI $16 S$ ribosomal RNA sequence database (Madden 2013). To make species-level identifications, representative genomes were retrieved from NCBI and the whole-genome similarity metric Average Nucleotide Identity (ANI) was calculated for top 16S BLAST hits. Whole-genome comparisons with ANI values of greater than 95\% were considered to be the same species (Konstantinidis and Tiedje 2005; Goris et al. 2007). For whole-genome comparisons with ANI values less than $95 \%$, strains were labeled as Genus sp. (), with

1
2
3
4


5




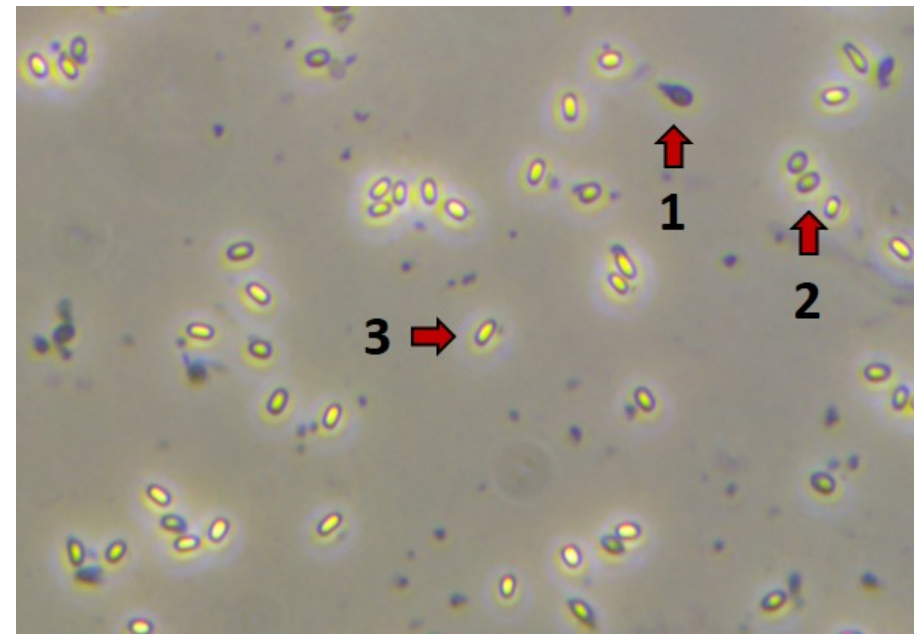

Figure 4 Phase-contrast microscopy (100X) of Terribacillus sp. (aidingensis) AS879 with examples of vegetative cells (1), endospores (2), and mature spores (3) visible.

the closest known relative indicated. Using Seaview Version 4.6.1 (Gouy et al. 2009; Galtier et al. 1996), 16S sequences were aligned using MUSCLE (Edgar 2004) and BioNJ trees (Gascuel 1997) were computed using Jukes \& Cantor (Jukes and Cantor 1969) pairwise phylogenetic distances with all gap containing sites excluded from the analysis.

\section{Data Availability}

Table S1 contains a list of all strains used in this study, RFUs measured using the terbium-DPA fluorescence assay, and DPA biosynthesis gene copy-number for each strain. File S1 contains an alignment of $16 \mathrm{~S}$ rRNA sequences. File S2 contains an alignment of $d p a A$ protein sequences. File S3 contains an alignment of $d p a B$ protein sequences. File S4 contains an alignment of Isf protein sequences.

\section{RESULTS}

Of the 67 strains included in this study (Table S1), all were Firmicutes representing the classes of Bacilli, Clostridia and Paenibacilli. As expected, all 49 strains of Bacillus and Paenibacillus (Figure 3, in black) were found to form endospores via phase-contrast microscopy (see Figures 1 and 2). DPA biosynthesis was detected in vitro (Table S1), and genome sequences revealed that all of these strains possessed known DPA synthase genes (Files S2 \& S3).

Ten strains from five genera that were re-classified from Bacillus to Brevibacillus, Fontibacillus, Lysinibacillus, Rummelibacillus, and Terribacillus which were hypothesized to produce DPA (Figure 3, highlighted in blue) were found to form endospores via phasecontrast microscopy (see Figure 4). DPA biosynthesis was detected in vitro (Table S1), and genome sequences revealed that all of these strains possessed known DPA synthase genes, dpaAB (Files S2 \& S3).

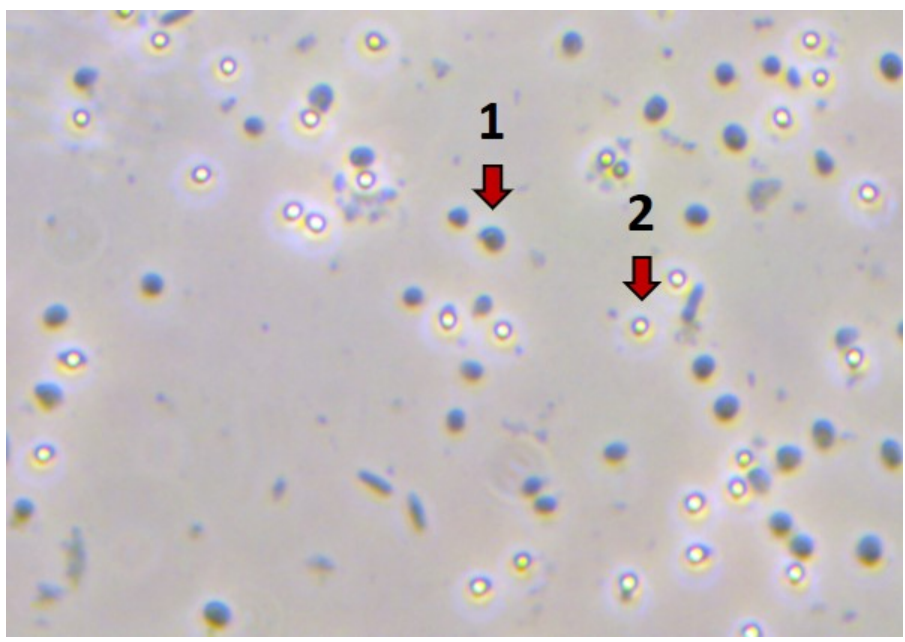

Figure 5 Phase-contrast microscopy (100X) of Clostridium aerotolerans AS472 with examples of vegetative cells (1) and mature spores (2) visible.

Eight strains of Clostridia which were expected to produce DPA were found to form endospores via phase-contrast microscopy (see Figures 5 and 6). DPA biosynthesis was detected in vitro (Table S1), and genome sequences revealed that two strains of Clostridium aerotolerans possessed homologs to known DPA sythase genes, $d p a A B$ (Files S2 \& S3). Genome sequences from the remaining six Clostridia (Figure 3, highlighted in red) did not have detectable known $d p a A B$ or etf $A$ genes (Table 1). etf $A$ contains a flavin mononucleotide (FMN), therefore a search was performed for other flavoproteins that contained a FMN and were common among the six Clostridia that lacked homologs to known DPA synthesis genes.

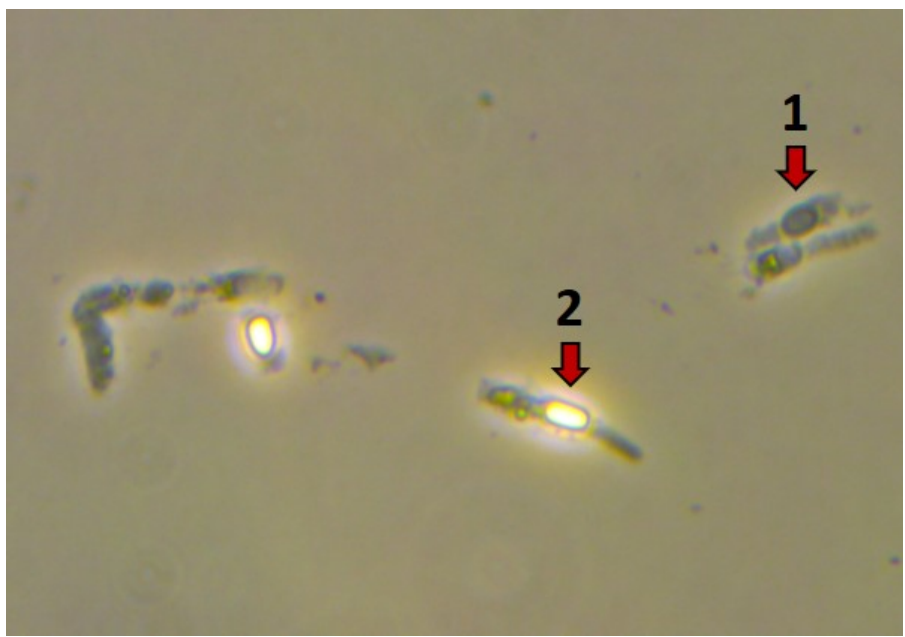

Figure 6 Phase-contrast microscopy (100X) of Clostridium scatologenes AS13 with examples of vegetative cells (1) and mature spores (2) visible.

While the Clostridium (cluster I) strains lack the recognized DPA biosynthesis genes, they all possess at least one copy of an ironsulfur flavoprotein (Isf) (File S4), and strains with more Isf copies produced more DPA (Table 1). Both etfA and Isf are thought to be involved in electron transport (Tsai and Saier Jr 1995; Becker et al. 1998). It is possible that these two genes have analogous activity, 
bioRxiv preprint doi: https://doi.org/10.1101/803486; this version posted October 16, 2019. The copyright holder for this preprint (which was not certified by peer review) is the author/funder, who has granted bioRxiv a license to display the preprint in perpetuity. It is made available under aCC-BY-NC-ND 4.0 International license.

\section{Table 1 DPA biosynthesis gene copy count and levels of DPA detected in strains of Clostridium}

\begin{tabular}{|c|c|c|c|c|c|}
\hline Taxonomy $^{a}$ & $d p a A^{b}$ & $d p a B^{c}$ & $e t f A^{d}$ & $I s f^{e}$ & $\mathrm{RFU}^{f}$ \\
\hline Clostridium beijerinckii AS471 & 0 & 0 & 0 & 10 & 103,839 \\
\hline Clostridium beijerinckii AS50 & 0 & 0 & 0 & 11 & 386,574 \\
\hline Clostridium beijerinckii AS7 & 0 & 0 & 0 & 6 & 65,340 \\
\hline Clostridium sp. (carboxidivorans) AS11 & 0 & 0 & 0 & 1 & 48,558 \\
\hline Clostridium sp. (scatologenes) AS13 & 0 & 0 & 0 & 1 & 45,462 \\
\hline Clostridium sp. (tyrobutyricum) AS66 & 0 & 0 & 0 & 1 & 47,567 \\
\hline
\end{tabular}

${ }^{a}$ For strains denoted as sp., the species in parenthesis is the closest recognized species

$b^{b}$ Dipicolinic acid synthase subunit $A$

${ }^{c}$ Dipicolinic acid subunit B

${ }^{d}$ Electron transfer flavoprotein $\alpha$-chain

${ }^{e}$ Iron-sulfur flavoprotein

${ }^{f}$ Relative fluorescence units

catalyzing the formation of DPA from L-2,3-dihydrodipicolinate (Figure 7). Future work including Isf gene knockout mutants that lack DPA production and/or observing upregulation of Isf expression during sporulation would be consistent with Isf having a role in DPA formation.

\section{DISCUSSION}

Here we have found that genera was a good predictor of DPA production, and added experimental evidence to support the production of DPA by additional Bacillaceae. This result, which is consistent with their previous classification as Bacillus, is yet an important observation given the functional diversity that these genera possess. In addition, we found the Clostridium (cluster I) lack recognized biosynthesis pathways for DPA production. This result, while similar to previous work (Orsburn et al. 2010), fails to confirm their findings and we propose an alternate genetic pathway in these strains.

Members of the Bacillaceae family found to produce DPA have recently been shown to possess many functions and utilities, and the survivability that DPA production adds, makes these strains ripe for use in novel products. For example, strains of Brevibacillus have been found to have larvicidal activity (Zubasheva et al. 2010), biological control of plant pathogens (Chandel et al. 2010; Liu et al. 2010), as well as improving shelf-life of fruits (Che et al. 2011). Fontibacillus strains have been shown to produce a novel and highly reusable pullanase (Alagöz et al. 2016) which is used as a processing aid for the production of ethanol or sweeteners from grain. Lysinibacillus species have been shown to degrade harmful insecticides (Singh et al. 2012), selectively desulfurize dibenzothiophene (Bahuguna et al. 2011), and produce mosquito larvicidal toxins (Lozano et al. 2011). In addition, strains can produce 10hydroxystearic acid from olive oil (Kim et al. 2012). Rummeliibacillus species have been shown to transform palm oil mill effluent to polyhydroxyalkanoate and biodiesel (Junpadit et al. 2017), enhance growth and health in tilapia (Yih et al. 2019), and has the potential for biomineralization (Mudgil et al. 2018). Finally, Terribacillus species have been found to produce a novel chitinase as well as antifungal enzymes that repress plant diseases (Essghaier et al. 2014). Given the wealth of functionalities that this family possesses, coupled with a long shelf-life and potential to survive in a variety of manufacturing processes due to DPA production, makes Bacillaceae well suited for industrial processes and an untapped well of biotechnology potential.
We have confirmed here that some Clostridia possess a DPA synthase homolog. We have also confirmed that Clostridium (cluster I) do not possess a DPA synthase homolog. Unlike previous findings, we were unable to identify etf $A$ in our assayed Clostridium (cluster I) strains. Despite the lack of $d p a A B$ and etf $A$ genes, these strains were still able to produce detectable quantities of DPA.

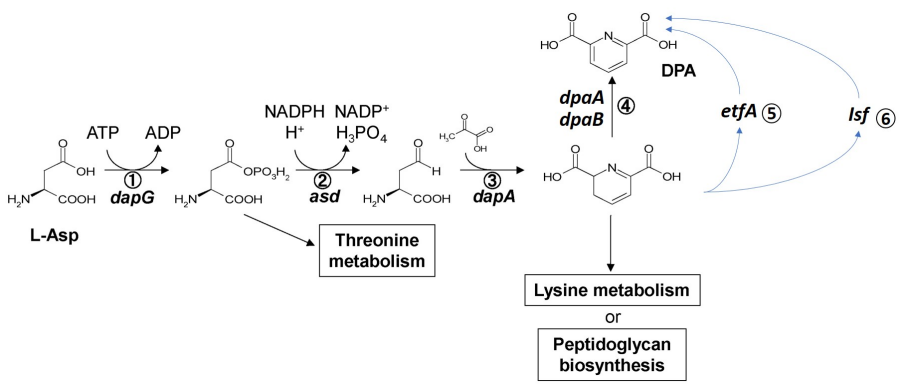

Figure 7 Dipicolinic acid biosynthesis pathways. ${ }^{1}$ dapG: aspartokinase; ${ }^{2}$ asd: aspartate-semialdehyde dehydrogenase; ${ }^{3}$ dapA: dihydrodipicolinate synthase; ${ }^{4} \mathrm{dpaAB}$ : dipicolinate synthase. ${ }^{5}$ etf $A$ : elctron transfer flavoprotein subunit $A ;{ }^{6}$ Isf: iron-sulfur flavoprotein. Modified from (Takahashi et al. 2015).

We propose the Isf gene product as an alternate pathway for DPA-production in Clostridium (cluster I). This alternate biosynthesis pathway for DPA synthesis represents a new potential route for bioengineering the production of DPA in other strains of bacteria via the addition of a single gene to the lysine pathway, particularly in anaerobes. Dipicolinic acid production has been engineered in bacterial strains using the traditional $d p a A B$ genes (Zelder et al. 2009; McClintock et al. 2018). DPA has numerous industrial uses, for example, the monomer can be used as a replacement for petroleum derived isophthalic acid in the synthesis of polyesters or polyamide copolymers (McClintock et al. 2018) resulting in a more biodegradable compound. The scalable synthesis of DPA using a variety of bacteria could increase its use as a replacement for other aromatic dicarboxylic acids.

Probiotics have been developed for human use as well as for use in animal feeds, and a large number of these formulations utilize spore-forming Bacillus (Hong et al. 2005). Effective probiotics need to thrive in anaerobic conditions and retain viability in aerobic conditions on the shelf, as well as cross the gastric barrier 
and enter the upper GI tract in a viable state following consumption. Probiotics utilizing DPA-producing endospores are proven to have better survivability during passage through the acidic stomach environment, show better survival during manufacturing, and have a longer shelf-life (Bader et al. 2012). The potential of Clostridia as probiotics has only recently been discussed (Cartman 2011). DPA-containing Clostridial endospores are ideal vehicles for overcoming the challenges probiotic bacteria encounter, as they can survive aerobic storage and remain viable while crossing the host gastric barrier, followed by germination in the anaerobic environment of the upper GI tract where they are well adapted to survive. Clostridium have been documented as members of healthy GI tracts in humans (Arumugam et al. 2011; Qin et al. 2010; Tap et al. 2009), have been shown to increase resistance against Irritable Bowel Disease (Atarashi et al. 2011), and can protect against C. difficile infection (Merrigan et al. 2009; Sambol et al. 2002). Given the survivability of DPA-producing Clostridia, and the recently highlighted benefits of Clostridium as members of the gut microbiota, they may prove to be an ideal probiotic.

In addition, an alternate biosynthesis pathway for DPA represents a new target for designing drugs to prevent contamination, as inhibiting the production of DPA would make endospores more susceptible to traditional manufacturing procedures. Many of the endospore-forming bacteria can survive food processing, decreasing the shelf-life of processed foods (e.g. Clostridium tyrobutyricum), and potentially making them unsafe to consume (e.g. Clostridium botulinum) (Daelman et al. 2013; Soni et al. 2016; André et al. 2017). Endospore-forming Clostridium also contain members that are known for their pathogenic potential, such as Clostridium (e.g. (C. perfringens, C. novyi, C. septicum, C. tetani, and C. difficile) (Ehling-Schulz et al. 2019; Wells and Wilkins 1996).

Here we have added experimental evidence to support the production of DPA by additional Bacillaceae and we have proposed an alternate pathway in Clostridium (cluster I) strains that lack recognized dipicolinic acid biosynthesis genes. By fully understanding the breadth and mechanisms by which DPA is produced, we can utilize endospore-forming bacteria in new ways: as novel bacterial strains added to products, for genes to create inputs for the polymer industry, and to be better equipped to control contaminating spores in industrial processes.

\section{ACKNOWLEDGEMENTS}

The authors would like to thank Frederic Kendirgi for his guidance during the research process. We are grateful to Chynna Gabotero, Mei Konishi, and Nicole Hensley for critical reading of the manuscript ahead of publication, and to Mylavarapu Venkatramesh for supervision during the study. This work was supported by Agrinos, and we would like to thank Agrinos management for their ongoing financial support.

\section{LITERATURE CITED}

Alagöz, D., D. Yildirim, H. K. Güvenmez, D. Sihay, and S. S. Tükel, 2016 Covalent immobilization and characterization of a novel pullulanase from fontibacillus sp. strain dshk 107 onto florisil ${ }^{\circledR}$ and nano-silica for pullulan hydrolysis. Applied Biochemistry and Biotechnology 179: 1262-1274.

Amador, J. A. and B. F. Taylor, 1990 Coupled metabolic and photolytic pathway for degradation of pyridinedicarboxylic acids, especially dipicolinic acid. Applied and Environmental Microbiology 56: 1352-1356.
André, S., T. Vallaeys, and S. Planchon, 2017 Spore-forming bacteria responsible for food spoilage. Research in Microbiology 168: 379-387.

Arima, K. and Y. Kobayashi, 1962 Bacterial oxidation of dipicolinic acid. Journal of Bacteriology 84: 759-764.

Arumugam, M., J. Raes, E. Pelletier, D. Le Paslier, T. Yamada, et al., 2011 Enterotypes of the human gut microbiome. Nature 473: 174.

Atarashi, K., T. Tanoue, T. Shima, A. Imaoka, T. Kuwahara, et al., 2011 Induction of colonic regulatory $\mathrm{t}$ cells by indigenous clostridium species. Science 331: 337-341.

Bach, M. L. and C. Gilvarg, 1966 Biosynthesis of dipicolinic acid in sporulating bacillus megaterium. Journal of Biological Chemistry 241: 4563-4564.

Bader, J., A. Albin, and U. Stahl, 2012 Spore-forming bacteria and their utilisation as probiotics. Beneficial Microbes 3: 67-75.

Bahuguna, A., M. K. Lily, A. Munjal, R. N. Singh, and K. Dangwal, 2011 Desulfurization of dibenzothiophene (dbt) by a novel strain lysinibacillus sphaericus dmt-7 isolated from diesel contaminated soil. Journal of Environmental Sciences 23: 975-982.

Becker, D. F., U. Leartsakulpanich, K. K. Surerus, J. G. Ferry, and S. W. Ragsdale, 1998 Electrochemical and spectroscopic properties of the iron-sulfur flavoprotein from methanosarcina thermophila. Journal of Biological Chemistry 273: 26462-26469.

Beverly, M. B., F. Basile, K. J. Voorhees, and T. L. Hadfield, 1996 A rapid approach for the detection of dipicolinic acid in bacterial spores using pyrolysis/mass spectrometry. Rapid Communications in Mass Spectrometry 10: 455-458.

Brandes Ammann, A., L. Kölle, and H. Brandl, 2011 Detection of bacterial endospores in soil by terbium fluorescence. International Journal of Microbiology 2011: 1-5.

Bulla, L., G. S. Julian, R. Rhodes, and C. Hesseltine, 1969 Scanning electron and phase-contrast microscopy of bacterial spores. Applied and Environmental Microbiology 18: 490-495.

Cartman, S. T., 2011 Time to consider clostridium probiotics? Future Microbiology 6: 969-971.

Chandel, S., E. J. Allan, and S. Woodward, 2010 Biological control of fusarium oxysporum $\mathrm{f}$. sp. lycopersici on tomato by brevibacillus brevis. Journal of Phytopathology 158: 470-478.

Che, J.-m., X.-f. Zheng, B. Liu, M.-x. Su, and Y.-j. Zhu, 2011 Preparation of brevibacillus brevis fjat-0809-glx angent and study on its effect on loquats (eriobotrya japonica). Storage \& Process 5.

Cowcher, D. P., Y. Xu, and R. Goodacre, 2013 Portable, quantitative detection of bacillus bacterial spores using surface-enhanced raman scattering. Analytical Chemistry 85: 3297-3302.

Daelman, J., A. Vermeulen, T. Willemyns, R. Ongenaert, L. Jacxsens, et al., 2013 Growth/no growth models for heat-treated psychrotrophic bacillus cereus spores under cold storage. International Journal of Food Microbiology 161: 7-15.

Daniel, R. and J. Errington, 1993 Cloning, dna sequence, functional analysis and transcriptional regulation of the genes encoding dipicolinic acid synthetase required for sporulation in bacillus subtilis. Journal of Molecular Biology 232: 468-483.

Driks, A., 2002 Overview: development in bacteria: spore formation in bacillus subtilis. Cellular and Molecular Life Sciences 59: 389-391.

Edgar, R. C., 2004 MUSCLE: multiple sequence alignment with high accuracy and high throughput. Nucleic Acids Research 32: 1792-1797.

Ehling-Schulz, M., D. Lereclus, and T. M. Koehler, 2019 The bacillus cereus group: Bacillus species with pathogenic potential. Microbiology Spectrum 7: 1-59. 
Errington, J., 2003 Regulation of endospore formation in bacillus subtilis. Nature Reviews Microbiology 1: 117-126.

Essghaier, B., C. Dhieb, H. Rebib, S. Ayari, A. R. A. Boudabous, et al., 2014 Antimicrobial behavior of intracellular proteins from two moderately halophilic bacteria: strain j31 of terribacillus halophilus and strain m3-23 of virgibacillus marismortui. Journal of Plant Pathology \& Microbiology 5: 1-7.

Finn, R. D., J. Clements, and S. R. Eddy, 2011 Hmmer web server: interactive sequence similarity searching. Nucleic acids research 39: W29-W37.

Fritze, D., 2004 Taxonomy of the genus bacillus and related genera: the aerobic endospore-forming bacteria. Phytopathology 94: 1245-1248.

Galperin, M. Y., 2013 Genome diversity of spore-forming firmicutes. Microbiology Spectrum 1: 1-27.

Galtier, N., M. Gouy, and C. Gautier, 1996 SEAVIEW and PHYLO_WIN: two graphic tools for sequence alignment and molecular phylogeny. Bioinformatics 12: 543-548.

Gascuel, O., 1997 BIONJ: an improved version of the NJ algorithm based on a simple model of sequence data. Molecular Biology and Evolution 14: 685-695.

Gerhardt, P., 1989 Spore thermoresistance mechanisms. In Regulation of Procaryotic Development, edited by I. Smith, R. Slepecky, and P. Setlow, pp. 17-37, American Society for Microbiology, Washington, D.C.

Goris, J., K. T. Konstantinidis, J. A. Klappenbach, T. Coenye, P. Vandamme, et al., 2007 Dna-dna hybridization values and their relationship to whole-genome sequence similarities. International Journal of Systematic and Evolutionary Microbiology 57: 81-91. Gouy, M., S. Guindon, and O. Gascuel, 2009 SeaView Version 4: A Multiplatform Graphical User Interface for Sequence Alignment and Phylogenetic Tree Building. Molecular Biology and Evolution 27: 221-224.

Gurevich, A., V. Saveliev, N. Vyahhi, and G. Tesler, 2013 Quast: quality assessment tool for genome assemblies. Bioinformatics 29: 1072-1075.

Henriques, A. O. and C. P. Moran, Jr., 2007 Structure, assembly, and function of the spore surface layers. Annual Review of Microbiology 61: 555-588.

Hillis, D. M. and J. J. Bull, 1993 An Empirical Test of Bootstrapping as a Method for Assessing Confidence in Phylogenetic Analysis. Systematic Biology 42: 182-192.

Hindle, A. and E. H. Hall, 1999 Dipicolinic acid (dpa) assay revisited and appraised for spore detection. Analyst 124: 1599-1604.

Hong, H. A., L. H. Duc, and S. M. Cutting, 2005 The use of bacterial spore formers as probiotics. FEMS Microbiology Reviews 29: 813-835.

Jukes, T. H. and C. R. Cantor, 1969 Evolution of protein molecules. In Mammalian Protein Metabolism, edited by H. N. Munro, volume 3, pp. 21-132, Academic Press, New York.

Junpadit, P., T. T. Suksaroj, and P. Boonsawang, 2017 Transformation of palm oil mill effluent to terpolymer polyhydroxyalkanoate and biodiesel using rummeliibacillus pycnus strain ts 8 . Waste and Biomass Valorization 8: 1247-1256.

Kim, B.-N., Y.-C. Joo, Y.-S. Kim, K.-R. Kim, and D.-K. Oh, 2012 Production of 10-hydroxystearic acid from oleic acid and olive oil hydrolyzate by an oleate hydratase from lysinibacillus fusiformis. Applied Microbiology and Biotechnology 95: 929-937.

Konstantinidis, K. T. and J. M. Tiedje, 2005 Genomic insights that advance the species definition for prokaryotes. Proceedings of the National Academy of Sciences 102: 2567-2572.

Liu, E., L. Bo, Q. Xiao, G. Feng, W. Yan, et al., 2010 Effects of the mixed inoculation of different biocontrol strains on colonization in tobacco and control of tobacco bacterial wilt. Chinese Journal of Biological Control 26: 200-205.

Logan, N. A. and G. Halket, 2011 Developments in the taxonomy of aerobic, endospore-forming bacteria. In Endospore-forming Soil Bacteria, edited by N. A. Logan and P. Vos, volume 3, pp. 1-29, Springer, New York.

Lozano, L. C., J. A. Ayala, and J. Dussán, 2011 Lysinibacillus sphaericus s-layer protein toxicity against culex quinquefasciatus. Biotechnology Letters 33: 2037-2041.

Madden, T., 2013 The blast sequence analysis tool. In The NCBI Handbook [Internet]. 2nd edition, National Center for Biotechnology Information (US).

McClintock, M. K., G. W. Fahnhorst, T. R. Hoye, and K. Zhang, 2018 Engineering the production of dipicolinic acid in e. coli. Metabolic Engineering 48: 208-217.

McKenney, P. T., A. Driks, and P. Eichenberger, 2013 The bacillus subtilis endospore: assembly and functions of the multilayered coat. Nature Reviews Microbiology 11: 33.

Merrigan, M. M., S. P. Sambol, S. Johnson, and D. N. Gerding, 2009 New approach to the management of clostridium difficile infection: colonisation with non-toxigenic c. difficile during daily ampicillin or ceftriaxone administration. International Journal of Antimicrobial Agents 33: S46-S50.

Moeller, R., M. Raguse, G. Reitz, R. Okayasu, Z. Li, et al., 2014 Resistance of bacillus subtilis spore dna to lethal ionizing radiation damage relies primarily on spore core components and dna repair, with minor effects of oxygen radical detoxification. Applied and Environmental Microbiology 80: 104-109.

Moir, A., 2003 Bacterial spore germination and protein mobility. Trends in Microbiology 11: 452-454.

Mudgil, D., S. Baskar, R. Baskar, D. Paul, and Y. S. Shouche, 2018 Biomineralization potential of bacillus subtilis, rummeliibacillus stabekisii and staphylococcus epidermidis strains in vitro isolated from speleothems, khasi hill caves, meghalaya, india. Geomicrobiology Journal 35: 675-694.

Murrell, W., 1969 Chemical composition of spores and spore structures. In Bacillus subtilis and its closest relatives, edited by G. Gould and A. Hurst, pp. 215-273, Academic Press, New York, NY.

Onyenwoke, R. U., J. A. Brill, K. Farahi, and J. Wiegel, 2004 Sporulation genes in members of the low $\mathrm{g}+\mathrm{c}$ gram-type-positive phylogenetic branch (firmicutes). Archives of Microbiology 182: 182192.

Orsburn, B. C., S. B. Melville, and D. L. Popham, 2010 Etfa catalyses the formation of dipicolinic acid in clostridium perfringens. Molecular Microbiology 75: 178-186.

Paredes-Sabja, D., B. Setlow, P. Setlow, and M. R. Sarker, 2008 Characterization of clostridium perfringens spores that lack spova proteins and dipicolinic acid. Journal of Bacteriology 190: 46484659.

Paredes-Sabja, D., P. Setlow, and M. R. Sarker, 2011 Germination of spores of bacillales and clostridiales species: mechanisms and proteins involved. Trends in Microbiology 19: 85-94.

Piggot, P. J. and D. W. Hilbert, 2004 Sporulation of bacillus subtilis. Current Opinion in Microbiology 7: 579-586.

Powell, J. F., 1953 Isolation of dipicolinic acid (pyridine-2: 6dicarboxylic acid) from spores of bacillus megatherium. Biochemical Journal 54: 210-211.

Qin, J., R. Li, J. Raes, M. Arumugam, K. S. Burgdorf, et al., 2010 A human gut microbial gene catalogue established by metagenomic sequencing. Nature 464: 59-65.

Rosen, D. L., C. Sharpless, and L. B. McGown, 1997 Bacterial spore
63 
detection and determination by use of terbium dipicolinate photoluminescence. Analytical Chemistry 69: 1082-1085.

Sambol, S. P., M. M. Merrigan, J. K. Tang, S. Johnson, and D. N. Gerding, 2002 Colonization for the prevention of clostridium difficile disease in hamsters. The Journal of Infectious Diseases 186: 1781-1789.

Seemann, T., 2014 Prokka: rapid prokaryotic genome annotation. Bioinformatics 30: 2068-2069.

Setlow, P., 1995 Mechanisms for the prevention of damage to dna in spores of bacillus species. Annual Review of Microbiology 49: 29-54.

Setlow, P., 2003 Spore germination. Current Opinion in Microbiology 6: 550-556.

Seyfried, B. and B. Schink, 1990 Fermentative degradation of dipicolinic acid (pyridine-2,6-dicarboxylic acid) by a defined coculture of strictly anaerobic bacteria. Biodegradation 1: 1-7.

Singer, E., B. Bushnell, D. Coleman-Derr, B. Bowman, R. M. Bowers, et al., 2016 High-resolution phylogenetic microbial community profiling. The ISME Journal 10: 2020-2032.

Singh, B., J. Kaur, and K. Singh, 2012 Transformation of malathion by lysinibacillus sp. isolated from soil. Biotechnology Letters 34: 863-867.

Soni, A., I. Oey, P. Silcock, and P. Bremer, 2016 Bacillus spores in the food industry: A review on resistance and response to novel inactivation technologies. Comprehensive Reviews in Food Science and Food Safety 15: 1139-1148.

Stragier, P., 2002 A gene odyssey: exploring the genomes of endospore-forming bacteria. In Bacillus subtilis and its closest relatives, edited by A. Sonenshein, J. Hoch, and R. Losick, pp. 519-525, American Society of Microbiology, Washington, D.C.

Takahashi, F., N. Sumitomo, H. Hagihara, and K. Ozaki, 2015 Increased dipicolinic acid production with an enhanced spovf operon in bacillus subtilis and medium optimization. Bioscience, Biotechnology, and Biochemistry 79: 505-511.

Tap, J., S. Mondot, F. Levenez, E. Pelletier, C. Caron, et al., 2009 Towards the human intestinal microbiota phylogenetic core. Environmental Microbiology 11: 2574-2584.

Taylor, B. F. and J. A. Amador, 1988 Metabolism of pyridine compounds by phthalate-degrading bacteria. Applied and Environmental Microbiology 54: 2342-2344.

Tsai, M. and M. Saier Jr, 1995 Phylogenetic characterization of the ubiquitous electron transfer flavoprotein families etf- $\alpha$ and etf- $\beta$. Research in Microbiology 146: 397-404.

Wang, Y., Y. Yue, H. Li, Q. Zhao, Y. Fang, et al., 2011 Dye-loaded zeolite 1@ silica core-shell composite functionalized with europium (iii) complexes for dipicolinic acid detection. Photochemical \& Photobiological Sciences 10: 128-132.

Wells, C. L. and T. D. Wilkins, 1996 Clostridia: sporeforming anaerobic bacilli. In Medical Microbiology. 4th edition, edited by S. Baron, pp. 1012-1045, University of Texas Medical Branch, Galveston, TX.

Wolska, K. I., A. M. Grudniak, and A. Kraczkiewicz-Dowjat, 2007 Genetic and physiological regulation of bacterial endospore development. Polish Journal of Microbiology 56: 11-17.

Yih, T. H., S.-W. Chen, and S.-Y. Hu, 2019 Improvements in the growth performance, immunity, disease resistance, and gut microbiota by the probiotic rummeliibacillus stabekisii in nile tilapia (oreochromis niloticus). Fish \& Shellfish Immunology 92: 265-275.

Yilmaz, M. D., S.-H. Hsu, D. N. Reinhoudt, A. H. Velders, and J. Huskens, 2010 Ratiometric fluorescent detection of an anthrax biomarker at molecular printboards. Angewandte Chemie Inter- national Edition 49: 5938-5941.

Zelder, O., W. K. Jeong, C. Klopprogge, A. Herold, and H. Schröder, 2009 Method for the production of dipicolinate. WO2009098046A1.

Zubasheva, M., L. Ganushkina, T. Smirnova, and R. Azizbekyan, 2010 Larvicidal activity of crystal-forming strains of brevibacillus laterosporus. Applied Biochemistry and Microbiology 46: 755-762.
63 